\title{
EVALUASI KESESUAIAN LAHAN UNTUK BUDIDAYA TANAMAN CABAI (CAPSICUM ANNUM) DI KECAMATAN TOMPASO KABUPATEN MINAHASA
}

\author{
Brenda Kurnia Momongan ${ }^{1}$, Helena Sri Sulastriningsih ${ }^{2}$ \\ ${ }^{1}$ Mahasiswa Program Studi Geografi, Fakultas Ilmu Sosial, Universitas Negeri Manado \\ ${ }^{2}$ Program Studi Geografi, Fakultas Ilmu Sosial, Universitas Negeri Manado \\ e-mail: hssulastri142@gmail.com
}

\begin{abstract}
In North Sulawesi, especially in the District of Tompaso, Minahasa District there are many agricultural lands, this area has a good soil structure for farming because it is close to Mount Soputan, but although the land in this area is quite fertile, chili cultivation is lacking, this research aims to study the suitability evaluation land for chilli cultivation in the Tompaso District of Minahasa Regency, this study used a survey method with the land unit approach as the unit of analysis, in this study land units were obtained from overlapping land use maps, slope maps, slope maps, soil type maps, landforms, and land unit. The population consists of 6 units of paddy fields, forest areas, mixed plantations, dry land agriculture, settlements, open land. Data collection techniques such as observation, documentation. Data analysis techniques to determine the land suitability class from chilli cultivation using scoring techniques by matching parameters and land suitability classes so that the land suitability map for chilli cultivation is obtained in Tamato District, Minahasa District. The results showed that the level of land suitability for chilli cultivation is included in the S1 land suitability class, with a limiting factor, which is an unknown type of pest and the method to overcome it.
\end{abstract}

Keywords: The Land Suitability, Chilli Plants

\begin{abstract}
Abstrak: Di Sulawesi Utara khususnya di Kecamatan Tompaso Kabupaten Minahasa banyak terdapat lahan pertanian, daerah ini memiliki sktruktur tanah yang baik untuk bercocok tanam dikarena dekat dengan Gunung Soputan, namun meskipun tanah didaerah ini cukup subur budidaya tanaman cabai kurang, Penelitian ini bertujuan untuk mengkaji tentang evaluasi kesesuaian lahan untuk budidaya tanaman cabai diwilayah Kecamatan Tompaso Kabupaten Minahasa,penelitian ini mengguanakan metode survey dengan pendekatan satuan lahan sebagai unit satuan analisisnya, dalam penelitian ini satuan lahan diperoleh dari tumpang susun peta penggunaan lahan, peta kemiringan lereng, peta jenis tanah, bentukan lahan, dan unit lahan. Populasi terdiri dari 6 satuan lahan sawah, kawasan hutan, perkebunan campuran, pertanian lahan kering, pemukiman, lahan terbuka. Teknik pengumpulan data berupa observasi, dokumentasi. Teknik analisis data untuk mengetahui kelas kesesuaian lahan dari budidaya tanaman cabai ini menggunakan teknik skoring dengan mencocokan parameter dan kelas kesesuaian lahan sehingga didapatkannya peta kesesuaian lahan untuk budidaya tanaman cabai Di Kecamatam Tompaso Kabupaten Minahasa. Hasil penelitian menunjukan bahwa tingkat kesesuaian lahan untuk budidaya tanaman cabai termasuk dalam kelas kesesuaian lahan S1, dengan factor pembatas yaitu hama yang belum diketahui jenisnya dan cara yang mengatasinya.
\end{abstract}

Kata Kunci: Evaluasi, Kesesuaian Lahan, Tanaman Cabai

\section{PENDAHULUAN}

Tanah merupakan salah satu faktor penting yang dibutuhkan manusia dalam menunjang kelangsungan kegiatan hidupnya. Sebagai tempat untuk pemukiman, pertanian dan lain-lain. Kegiatan pertanian, tanah merupakan tempat untuk bercocok tanam sehingga dapat berkembang dan berproduksi. Iklim tropis, tempat yang luas, tanah yang subur, menyebabkan Indonesia merupakan tempat yang baik untuk pembudidayaan bermacam macam komuditi pertanian. Salah satu produk pertanian yaitu buah-buahaan.

Meningkatnya kebutuhan dan persaingan penggunaan lahan baik untuk keperluan produksi pertanian dan non pertanian di perlukan pemikiran yang seksama dalam mengambil keputusan pemanfaatan yang paling 
menguntungkan dari sumber daya lahan yang terbatas, dan sementara itu juga harus melakukan tindakan konservasinya untuk penggunaan masa mendatang.

Di Sulawesi Utara khususnya di Kabupaten Minahasa Kecamatan Tompaso banyak terdapat lahan pertanian yang berada dibawah kaki gunung soputan oleh karena itu lahan pertanian di daerah ini mempunyai tanah yang begitu subur cocok untuk bercocok tanam dengan berbagai macam komuditas tanaman. Walaupun tanah di wilayah lahan pertanian di daerah ini begitu subur sangatlah kurang tanaman seperti cabai di tanam di lahan pertanian tersebut, tidak seperti tanaman jagung, tomat, dan lain-lain yang cukup banyak ditanam di wilayah Kecamatan Tompaso. Dalam hal ini peneliti ingin mengetahui kecocokan jenis tanaman cabai di lahan pertanian seperti ini.

\section{Identifikasi Masalah}

Lahan di Kecamatan Tompaso yang cukup luas untuk budidaya tanaman cabai, hanya saja produksi cabai rendah dikarenakan teknik budidayanya yang keliru.

\section{Perumusan Masalah}

1. Bagaimana caranya agar produksi cabai di Kecamatan Tompaso dapat meningkat"

2. Bagaimana tingkat kesesuaian lahan untuk budidaya tanaman cabai di Kecamatan Tompaso"

\section{Tujuan Penelitian}

Berdasarkan rumusan masalah, maka tujuan penelitian ini adalah untuki mengetahui tingkat kesesuaian lahan untuk budidaya tanaman cabai di Kecamatan Tompaso Kabupaten Minahasa".

\section{Manfaat Penelitian}

1. Dapat digunakan sebagai literatur untuk mempelajari hal-hal yang berkaitan dengan kesesuaian tanaman dalam hal ini tanaman cabai dalam penelitian-penelitian selanjutnya.

2. Bagi pembaca, dapat memberikan informasi dan wawasan mengenai kesesuaian lahan di Kecamatan Tompaso Kabupaten Minahasa untuk tanaman cabai.

3. Bagi penulis, dapat memperoleh data tingkat kesesuaian lahan tanaman cabai di Kecamatan Tompaso Kabupaten Minahasa.

\section{METODE}

Untuk menentukan kesesuaian lahan dalam satu jenis tanaman dengan kualitas dan karakteristik lahan yang menjadi daerah penelitian, maka penelitian ini menggunakan pendekatan satuan lahan atau land unit dengan mencocokkan (matching) kualitas dan karakteristik lahan kemudian diperoleh melalui overlay peta.

Variabel atau objek dalam penelitian ini yaitu kualitas dan karakteristik lahan sebagai parameter penentuan kelas kesesuaian lahan dari tanaman cabai, yang meliputi suhu rata rata $\left({ }^{\circ} \mathrm{C}\right)$, jumlah curah hujan $(\mathrm{mm})$, drainase, tekstur tanah. Ph tanah, kemiringan lereng (\%).

\section{Cara Memperoleh Data}

1. Observasi, dilakukan pada awal kegiatan untuk orientasi daerah penelitian.

2. Deskripsi umum daerah penelitian yang meliputi letak astronomis, letak administrasi, luas wilayah diambil dari Badan Pusat Statistik Kabupaten Minahasa.

3. Penggunaan lahan daerah penelitian diambil dari Unit Pelaksana Teknis (UPT) Pertanian Kecamatan Tompaso.

4. Data kemiringan lereng, kondisi tanah, kondisi iklim, keasaman tanah $(\mathrm{pH})$, tekstur dan drainase, diambil dari Unit Pelaksana Teknis Pertanian Kecamatan Tompaso.

5. Peta yang meliputi, peta bentukan lahan, petah tanah, peta penggunaan lahan, peta topografi dan kemiringan lereng, peta unit lahan, dan peta kesesuaian lahan.

Pengukuran lapangan meliputi kegiatan pengukuran langsung di lapangan tanpa harus diuji di laboratorium, meliputi:

1. Ketersediaan air, data ini diperoleh melalui wawancara langsung dengan beberapa petani cabai, dan melakukan observasi atau pengamatan dilapangan.

2. Drainase atau lengkungan saluran air atau juga pembuangan masa air secara alami ataupun buatan, data ini diperoleh dengan observasi atau pengamatan dilapangan, dan wawancara kepada beberapa petani cabai.

Alat dan Bahan

1. Perangkat Keras (Hardware). AMD A8 QUAD CORE X4, 4GB RAM, dan 500GB HDD, merupakan alat yang digunakan untuk menjalankan program, pemerosesan data, 
dan penyimpanan data yang dibutuhan dalam penelitian.

2. Printer.Alat untuk mencetak peta, laporan, serta hasil pengelolaan data lainnya yang dibutuhkan dalam penelitiaan.

3. Perangkat lunak (software)

- ArcView, SAS Planet atau perangkat lunak system informasi geografi yang membantu dalam pembuatan peta.

- Buku catatan dan alat tulis

- Kamera, digunakan untuk mengambil gambar objek penelitian dilapangan yang sesuai dengan sasaran penelitian.

Teknik analisis data yang digunakan dalam penelitian ini adalah overlay peta, dengan teknik pengharkatan (skoring). Teknik analisis skoring digunakan untuk memberikan nilai pada masing-masing karakteristik parameter dari subsub variabel agar dapat dihitung nilainya serta dapat ditentukan peringkatnya.

Penilaian dari masing-masing parameter pada setiap satuan lahan diharkatkan. Metode matching dilakukan setelah overlay (tumpang susun) yaitu untuk membandingkan antara kualitas dan karakteristik lahan dengan parameter yang diukur dilapangan atau dari data yang tersedia dengan krtiteria kelas kesesuaian lahan yang disusun sebagai persyaratan penggunaan atau persyaratan tumbuh kembang tanaman yang akan dievaluasi.

\section{HASIL DAN PEMBAHASAN}

\section{Letak dan Luas}

Secara geografis Kecamatan Tompaso terletak pada koordinat $1^{\circ} 17^{1}-1^{\circ} 19^{1} \mathrm{LU}$ dan $124^{\circ} 80^{1}-124^{\circ} 82^{1}$ BT. Secara Administratif Kecamatan Tompaso terletak di Kabupaten Minahasa Provinsi Sulawesi Utara.

Wilayah Kecamatan Tompaso terletak pada ketinggian tanah rata-rata $792 \mathrm{mdpl}$ atau 2,598 kaki, dengan suhu maksimum $22,8^{\circ} \mathrm{C}$ dan suhu minimum $22,1^{\circ} \mathrm{C}$, sedangkan kelembapan udara rata-rata berkisar antara 89-93\%. (Kecamatan Tompaso tahun 2018). Kecamatan Tompaso memiliki luas wilayah $4,682 \mathrm{Ha}$ $\left(32,21 \mathrm{Km}^{2}\right)$.

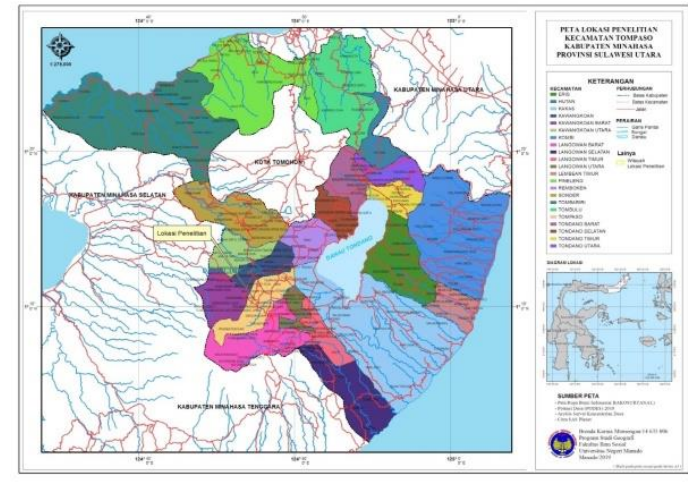

Gambar 1. Peta Lokasi Penelitian

\section{Keadaan Iklim}

Kecamatan Tompaso beriklim tropis yang memiliki 2 musim yaitu musim penghujan dan musim kemarau, Dengan rata-rata suhu minimum dan maksimum berkisar antara 22,1 sampai $22,8^{\circ} \mathrm{C}$, dengan suhu tertinggi terdapat pada tahun 2015 dengan suhu $23,0^{\circ} \mathrm{C}$.

Curah hujan yang diperlukan untuk penyusunan suatu rancangan pemanfaatan air adalah curah rerata daerah yang bersangkutan dan bukan pada suatu titik tertentu. jumlah hujan rerata tahunan adalah $3245.31 \mathrm{~mm}$, dengan nilai rerata tertinggi terjadi pada bulan Januari yaitu $442.42 \mathrm{~mm}$ dan jumlah hujan rerata terendah terjadi pada bulan Agustus yaitu $132.36 \mathrm{~mm}$.

\section{Keadaan Geologi dan Tanah}

Secara geografis Kecamatan Tompaso terletak pada koordinat $1^{\circ} 17^{1}-1^{\circ} 1^{1} \mathrm{LU}$ dan $124^{\circ} 80^{1}-124^{\circ} 82^{1}$ BT. Kondisi geologi pada daerah penelitian ini didominasi dengan batuan vulkanis berumur tersier (post miosen) sampai resen. "Litologi yang tersusun pada daerah penelitian ini terdiri dari pertama tuff atau batu putih dengan batuan piroklastik yang mengandung debu vulkanis yang dikeluarkan selama letusan gunung berapi, kedua riolit atau batuan beku vulkanik dengan komposisi felsic yang dapat memiliki tekstur seperti kaca, afanitik hingga porfiritik, juga andesit, pitchstone, breksi piroklastik, dan batuapung".

Struktur geologi yang berada dipulau Sulawesi memperlihatkan keadaan yang sangat kompleks. Hal ini disebabkan karena pulau Sulawesi merupakan daerah yang banyak mendapat pengaruh pertemuan dari beberapa lempeng samudera dan benua. pada daerah penelitian ini adalah sesar soputan yang berarah ke timur laut - tenggara dan sesar tempang berarah utara - selatan. Dan struktur yang 
berupa kelurusan yang berarah relatif ke utara juga terdapat didaerah tompaso

Jenis tanah yang ada di Kecamatan Tompaso adalah jenis tanah regosol dengan jenis tanah yang memiliki beberapa varian warna yakni kuning, coklat kemerahan, coklat, serta coklat kekuningan yang merupakan tanah vulkanis yang berasal dari gunung berapi hal ini dikarenakan kecamatan Tompaso dekat dengan gunung berapi.

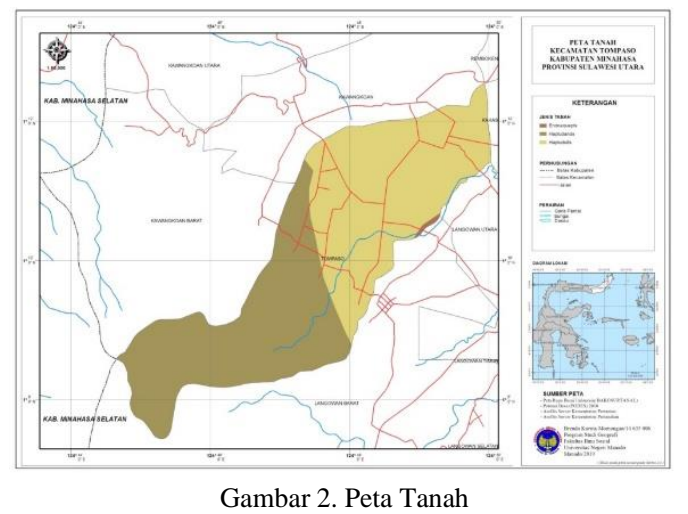

Penggunaan Lahan

Tabel 1. Penggunaan Lahan Kecamatan Tompaso

\begin{tabular}{ll}
\hline Penggunaan Lahan & Luas $($ ha $)$ \\
\hline Sawah & 923 \\
Kawasan hutan & 514 \\
Perkebunan campuran & 232 \\
Pertanian lahan kering & 1,013 \\
Pemukiman & 295 \\
Lahan terbuka & 32 \\
Jumlah & 3,020 \\
\hline
\end{tabular}

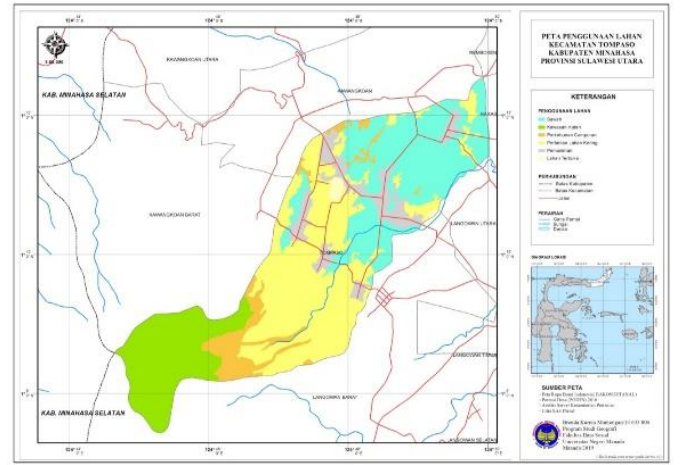

Gambar 3. Peta Penggunaan Lahan

Kemiringan Lereng

Kecamatan Tompaso termasuk kompleks mulai dari dataran, perbukitan dengan sudut lereng antara 2\% - 40\% (datar sampai dengan curam).

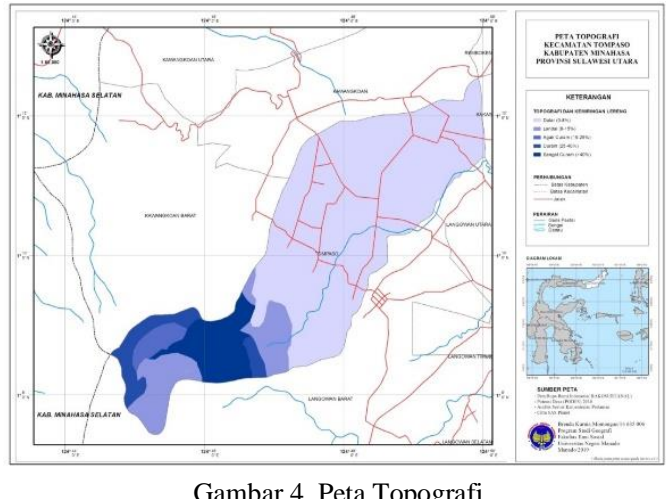

Keasaman Tanah

Tingkat keasaman atau kadar $\mathrm{pH}$ dikecamatan tompaso berkisar antara 5-7, kondisi tanah dengan $\mathrm{Ph}$ netral maka tumbuhan akan lebih mudah menyerap unsur hara dan menjaga keseimbangan mikroorganisme yang terdapat dalam tanah.

\section{Bentukan Lahan}

Bentukan lahan pada daerah penelitian terdiri dari 2 bentukan yaitu fluvial dan vulkanik, bentukan lahan vulkanik lebih dominan pada daerah penelitian ini yaitu $98 \%$, sedangkan bentukan fluvial hanya terdapat pada bagian selatan didesa tember yaitu $2 \%$. Dapat dilihat pada peta bentukan lahan dibawah.

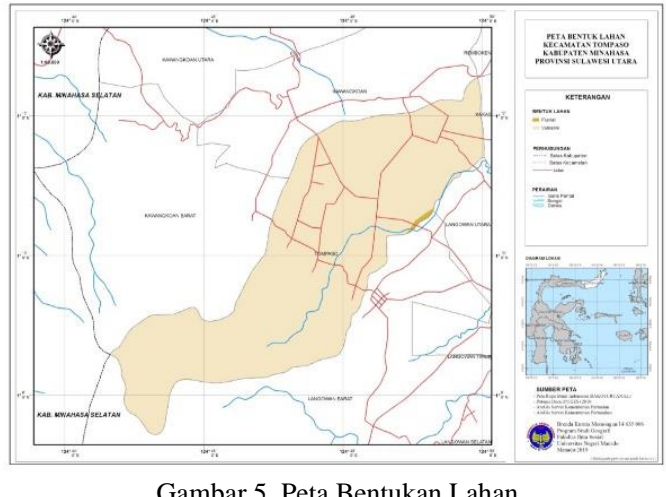

Satuan Lahan

Peta satuan lahan disusun dengan cara tumpang susun peta bentukan lahan, topografi dan kemiringan lereng, penggunaan lahan dan peta tanah. hasil tumpang tindih dari peta-peta tersebut maka didapatlah 23 satuan lahan. 
Tabel 2. Satuan Lahan Daerah Penelitian

\begin{tabular}{|c|c|c|c|c|c|}
\hline $\mathrm{No}$ & Simbol Satuan Lahan & Bentuk Lahan & Lereng \% & Jenis Tanah & Penggunaan \\
\hline 1 & F I End Lt & Fluvial & $(0-8 \%)$ & Endoaquepts & Lahan Terbuka \\
\hline 2 & F I End P & Fluvial & $(0-8 \%)$ & Endoaquepts & Pemukiman \\
\hline 3 & F I End Pk & Fluvial & $(0-8 \%)$ & Endoaquepts & Pertanian Lahan Kering \\
\hline 4 & F I End S & Fluvial & $(0-8 \%)$ & Endoaquepts & Sawah \\
\hline 5 & V I Dults Lt & Vulkanik & $(0-8 \%)$ & Hapludults & Lahan Terbuka \\
\hline 6 & V I Dults P & Vulkanik & $(0-8 \%)$ & Hapludults & Pemukiman \\
\hline 7 & V I Dults Pc & Vulkanik & $(0-8 \%)$ & Hapludults & Perkebunan campuran \\
\hline 8 & V I Dults Pk & Vulkanik & $(0-8 \%)$ & Hapludults & Pertanian Lahan Kering \\
\hline 9 & V I Dults S & Vulkanik & $(0-8 \%)$ & Hapludults & Sawah \\
\hline 10 & V I Hap P & Vulkanik & $(0-8 \%)$ & Hapludands & Pemukiman \\
\hline 11 & V I Hap Pc & Vulkanik & $(0-8 \%)$ & Hapludands & Perkebunan Campuran \\
\hline 12 & V I Hap Pk & Vulkanik & $(0-8 \%)$ & Hapludands & Pertanian Lahan Kering \\
\hline 13 & V I Hap S & Vulkanik & $(0-8 \%)$ & Hapludands & Sawah \\
\hline 14 & V II Hap H & Vulkanik & $(8-15 \%)$ & Hapludands & Kawasan Hutan \\
\hline 15 & V II Hap Pc & Vulkanik & $(8-15 \%)$ & Hapludands & Perkebunan Campuran \\
\hline 16 & V II Hap Pk & Vulkanik & $(8-15 \%)$ & Hapludands & Pertanian Lahan Kering \\
\hline 17 & V III Hap H & Vulkanik & $(15-25 \%)$ & Hapludands & Kawasan Hutan \\
\hline 18 & V IV Hap H & Vulkanik & $(25-40 \%)$ & Hapludands & Kawasan Hutan \\
\hline 19 & V IV Hap Pc & Vulkanik & $(25-40 \%)$ & Hapludands & Perkebunan Campuran \\
\hline 20 & V IV Hap Pk & Vulkanik & $(25-40 \%)$ & Hapludands & Pertanian Lahan Kering \\
\hline 21 & V V Hap H & Vulkanik & $(40 \%)$ & Hapludands & Kawasan Hutan \\
\hline 22 & V V Hap Pc & Vulkanik & $(40 \%)$ & Hapludands & Perkebunan Campuran \\
\hline 23 & V V Hap Pk & Vulkanik & $(40 \%)$ & Hapludands & Pertanian Lahan Kering \\
\hline
\end{tabular}

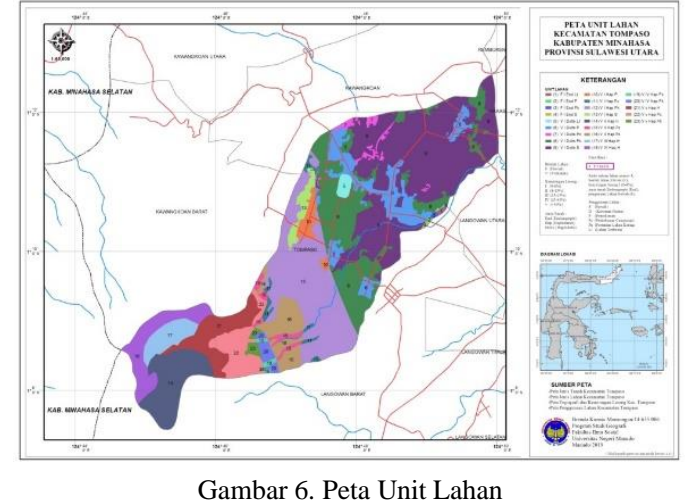

Penduduk dan Mata Pencaharian

Jumlah penduduk Kecamatan Tompaso pada tahun 2018 adalah 7381 jiwa dimana jumlah laki-laki 3643 jiwa dan jumlah perempuan 3738 jiwa.

Luas lahan Kecamatan Tompaso sebagian besar adalah lahan pertanian maka mata pencaharian penduduknya mayoritas adalah petani.

\section{Karakteristik dan Kualitas Lahan}

Karakteristik lahan adalah sifat sifat lahan yang dapat dinilai atau diamati, parameter kriteria dalam kesesuaian lahan tanaman cabai adalah 6 , meliputi tempratur $\left({ }^{\circ} \mathrm{C}\right)$, curah hujan $(\mathrm{mm})$, drainase, tekstur tanah, $\mathrm{Ph}$ tanah, kemiringan lereng (\%)
Berdasarkan data yang diperoleh suhu udara rata rata tahunan didaerah penelitian adalah $22,8^{\circ} \mathrm{C}$.

Berdasarkan bulan kering dengan jumlah $<60 \mathrm{~mm}$ yang diperoleh dari curah hujan perbulannya dalm periode 10 tahun dan jumlah hujan tahunan. Hasil perhitungan rata rata bulan kering periode 10 tahun adalah 1 bulan, dan jumlah hujan rata rata tahunan adalah 3.245,31 $\mathrm{mm}$.

Berdasarkan peta dan table satuan lahan, drainase lahan pada no $3,4,7,8,9,12,13$ adalah baik sedangkan pada no $11,15,16,19$, 20, drainase tanahnya bersifat sedang. Pada satauan lahan 23 drainasenya sangat terhambat. Maka drainase yang baik mendominan pada daerah dengan jenis tanah Hapludults atau pada bagian timur dan tenggara.

Sedangkan untuk tekstur berdasarkan peta dan Table 3.2 satuan lahan no 10,11, 12, 13, 14, $15,16,17,18,19,20,21,22,23$ bertekstur lempung dan berpasir, sedangkan pada no 1,2 , 3,4 , bertekstur liat dan berpasir, sedangkan pada no 5, 6, 7, 8, 9 bertekstur lempung, berdebu, liat dan pasir.

Tingkat keasaman atau kadar $\mathrm{pH}$ dikecamatan tompaso berkisar antara 5-7, kondisi tanah dengan $\mathrm{Ph}$ netral maka tumbuhan akan lebih mudah menyerap unsur hara dan 
menjaga keseimbangan mikroorganisme yang terdapat dalam tanah.

Kecamatan Tompaso termasuk kompleks mulai dari dataran, perbukitan dengan sudut lereng antara $2 \%$ - 40\% (datar sampai dengan curam).

\section{Kesesuaian Lahan Daerah Penelitian}

Hasil dari kesesuaian lahan penelitian didaerah penelitian ini adalah kesesuaian lahan yang dihasilkan berdasarkan data yang ada. Penentuan kelas kesesuaian lahan untuk budidaya tanaman cabai diperoleh dari membandingkan antara karakteristik lahan sebagai parameter dari setiap satuan lahan dengan persyaratan tumbuh tanaman cabai sebagai acuan. Hasil penelitian menunjukan bahwa Kecamatan Tompaso mempunyai kelas kesesuaian lahan untuk tanaman cabai, yaitu S1 dan S2 dan 6 sub kelas yaitu Tempratur, Drainase, Tekstur, $\mathrm{pH}$, dan Kemiringan Lereng.

Lahan kelas S1 memiliki luas $2.055 \mathrm{Ha}$. Satuan lahan yang termasuk S1 adalah Tempratur, Drainase, dan Tekstur tanah. Lahan S2 memiliki luas $965 \mathrm{Ha}$. Satuan lahan yang termasuk S2 adalah Curah Hujan, Ph Tanah, Kemiringan Lereng. Lahan S2 memilik penghambat berupa curah hujan dengan jumlah $500 \mathrm{~mm}$ hanya saja dapat diperbaiki dengan adanya drainase, kemudian $\mathrm{pH}$ tanah dapat diubah menjadi lahan S1 dengan cara pengapuran, dan Kemiringan lereng pengahambat ini dapat diubah menjadi lahan dengan kelas kesesuaian S1 dengan cara terasering, sedangkan pengahmbat berupa ketinggian atau curam tidak dapat diatasi karena ini merupakan faktor alami.

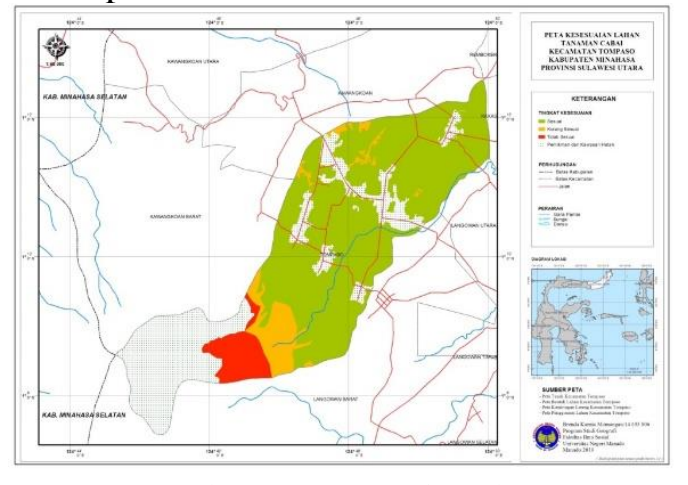

Gambar 7. Peta Kesesuaian Lahan

Faktor pembatas muncul karena adanya ketidaksesuaian sifat fisik disetiap satuan lahan dengan persyaratan tumbuh tanaman cabai. Usaha dilakukan untuk meningkatkan produktifitas tanamn cabai dengan diberikannya perlakuan perlakuan perbaikan sesuain dengan pembatasnya. Untuk faktor pembatas berupa kandungan unsur hara bisa diatasi dengan pemupukan, sedangkan dengan keasaman tanah dapat diatasi dengan pengapuran.

\section{Pembahasan}

Tabel 3. Kelas Kesesuaian Lahan Untuk Tanaman Cabai

\begin{tabular}{lll}
\hline $\begin{array}{l}\text { Kelas Satuan } \\
\text { Lahan }\end{array}$ & Jumlah Harkat & Kesesuaian Lahan \\
\hline I & $21-25$ & Sangat Sesuai (S1) \\
II & $16-20$ & Cukup Sesuai (S2) \\
III & $11-15$ & Sesuai Marginal (S3) \\
IV & $6-10$ & Tidak Sesuai (N) \\
\hline
\end{tabular}

Sumber: Hasil Perhitungan Lebar Kelas Interval

Tabel 4. Hasil Kelas Kesesuaian Lahan

\begin{tabular}{lllll}
\hline $\begin{array}{l}\text { Persyaratan } \\
\text { Penggunaan }\end{array}$ & \multicolumn{3}{c}{ Kelas Kesesuaian Lahan } & \\
\hline $\begin{array}{l}\text { Karakteristik } \\
\text { Lahan }\end{array}$ & S1 & S2 & S3 & $\mathrm{N}$ \\
$\begin{array}{l}\text { Temperatur } \\
\left({ }^{\circ} \mathrm{C}\right)\end{array}$ & $22,8-22,1$ & - & - & - \\
$\begin{array}{l}\text { Curah Hujan } \\
(\mathrm{mm})\end{array}$ & - & $500-600$ & - & - \\
$\begin{array}{l}\text { Drainase } \\
\text { Tekstur }\end{array}$ & Baik & - & - & - \\
pH & Sedang & - & - & - \\
$\begin{array}{l}\text { Kemiringan } \\
\text { Lereng }\end{array}$ & - & $5,0-7,5$ & - & - \\
\hline Sumber : hasil perhitungan kelas kesesuaian lahan &
\end{tabular}

Hasil penelitian daerah kesesuaian lahan untuk budidaya tanaman cabai menunjukan angka S1 Dan S2 yang sesuai dan cukup sesuai untuk kriteria lahan budidaya tanaman cabai.

Tabel 5. Kelas Kesesuaian Lahan utnuk Budidaya Tanaman Cabai

\begin{tabular}{|c|c|c|c|c|}
\hline $\mathrm{No}$ & Kelas & Sub Kelas & Luas $(\mathrm{Ha})$ & Unit Lahan \\
\hline \multirow[t]{3}{*}{1.} & $\mathrm{~S} 1$ & Tempratur & $4,610 \mathrm{Ha}$ & V I Dults S \\
\hline & & Drainase & $3,452 \mathrm{Ha}$ & $\begin{array}{l}\text { V I Dults S, V I } \\
\text { Dults Pk }\end{array}$ \\
\hline & & Tekstur & $3,036 \mathrm{Ha}$ & $\begin{array}{l}\text { V I Hap Pk, V I } \\
\text { Dults S, V I } \\
\text { Dults Pk }\end{array}$ \\
\hline \multirow[t]{3}{*}{2.} & $\mathrm{~S} 2$ & $\begin{array}{l}\text { Curah } \\
\text { Hujan }\end{array}$ & $2,879 \mathrm{Ha}$ & $\begin{array}{l}\text { V I Dults S, V } \\
\text { v Hap H }\end{array}$ \\
\hline & & $\mathrm{pH}$ Tanah & $3,842 \mathrm{Ha}$ & $\begin{array}{l}\text { V v Hap Pc, V I } \\
\text { Dults Pk, V v } \\
\text { Hap H }\end{array}$ \\
\hline & & $\begin{array}{l}\text { Kemiringan } \\
\text { Lereng }\end{array}$ & $1,734 \mathrm{Ha}$ & $\begin{array}{l}\text { V v Hap H, V } \\
\text { IV Hap H }\end{array}$ \\
\hline
\end{tabular}

Sumber: Hasil Penelitian Satuan Lahan Untuk Budidaya Tanaman Cabai 


\section{KESIMPULAN}

1. Daerah penelitian ada pada kriteria sesuai untuk budidaya tanaman cabai dengan kelas kesesuaian lahan S1 (sesuai) dengan jumlah 3 satuan lahan yaitu Tempratur $\quad(4,610 \mathrm{Ha}), \quad$ Drainase $(3,452 \mathrm{Ha})$, Tekstur $(3,036 \mathrm{Ha})$, dan Kelas Kesesuaian Lahan S2 (cukup sesuai), dengan jumlah satuan lahan 3 yaitu Curah Hujan $(2,870 \mathrm{Ha}), \mathrm{Ph}$ Tanah $(3,842 \mathrm{Ha})$, dan Kemiringan Lereng $(1,734 \mathrm{Ha})$ ".

2. Faktor pembatas untuk kelas kesesuaian lahan S2 adalah Curah Hujan, Kemiringan Lereng dan $\mathrm{pH}$ Tanah.

3. Kelas Kesesuaian lahan S1 adalah lahan yang sesuai dan menjadi prioritas yang dapat dikembangakan untuk budidaya tanaman Cabai.

4. Kelas kesesuaian lahan S2 cukup sesuai untuk budidaya tanaman cabai namun harus ada perbaikan baik pada daerah yang curam maupun pada $\mathrm{Ph}$ tanah dan juga curah hujan yang dapat diperbaiki dengan drainase.

5. Kelas Kesesuaian lahan dengan didominasi dengan lereng yang curah pada Unit Lahan V v Hap H, sebaiknya diperuntukan untuk penggunaan lainnya sesuai dengan kelas kesesuaiannya.

\section{SARAN}

1. Satuan lahan pada kelas kesesuaian lahan S2 perlu diadakannya perbaikan kualitas lahan lewat factor pembatas agar kualitas lahan menjadi lebih baik dan dapat menghasilkan produksi-produksi terbaik.

2. Satuan Lahan yang memiliki faktor pembatas yang sulit untuk diperbaiki sebaiknya diperuntukan untuk penggunaan lainya sesuai dengan kelas kesesuaiannya.

\section{DAFTAR PUSTAKA}

Aditiyas, 2014. Analisis Spasial untuk Evaluasi Kesesuaian Lahan Tanaman Apel Di Kota Batu Jawa Timur. Jurnal Sumberdaya
Alam dan Lingkungan, Portal Jurnal Universitas Brawijaya

Abidin Dwi Sulistiyono, 2009. Evaluasi Kesesuaian Lahan dan Produktifitas Tanaman Jagung di DAS Grindulu Hulu Kabupaten Pacitan dan Ponorogo. Jurnal Sumberdaya Alam dan Lingkuangan.

Arsyad, 2010. Konservasi Tanah dan Air. Bogor : IPB Press

Badan Pusat Statistik Kabupaten Minahasa, 2018. Luas Wilayah Kecamatan Tompaso, Mata Pencaharian Penduduk Kecamatan Tompaso

Beek dan Bennema, 1973. dalam Karim 1993. Kualitas Lahan. Jurnal Capter II Universitas Sumatera Utara, http://repository.usu.ac.id/ChapterII.pdf

Direktorat Jendral Hortikultura Kementrian Pertanian, 2009. Daerah dengan Produksi Cabai Terbesar di Indonesia

FAO Arsyad, 1989. Pengertian Lahan. http://file.upi.edu

FAO Totok Gunawan, 2014. Kualitas Lahan, www.Indonesistudents.com

Nurhayani, 2009. Evaluasi Kesesuaian Lahan Tanaman Cabai (Capsicum Annum L.) Dusun Pamah Semilir..., 2006. Medan : USU Repository

Nur Aida Kusuma Waty. 2009. Evaluasi Kesesuaian Lahan Untuk Produktifitas Budidaya Tanaman Padi Gogo (Oriza Sativa) di Kecamatan Playen Kabupaten Gunung Kidul

Nursyamsi, D., 2015. Karakteristik dan Kesesuaian Lahan Tanaman Cabai, Science Inovation Networks. www.litbang.deptan.go.id diakses tanggal: 10 juli 2018

Purwowidodo, 1983. Pengertian Lahan. www.academia.edu

Quick Tracktor, 2016. Syarat Tumbuh Tanaman Cabai. www.PetaniQuick.com

Stasiun Klimatologi Kayuwatu, 2018. Hasil Perhitungan Rata-Rata Curah Hujan Daerah Penelitian Tahun 2016 dan 2017 